\title{
Perencanaan Pengendalian Lalu Lintas di Persimpangan Jalan Sekitar Jembatan Kuncir Kabupaten Nganjuk, Jawa Timur
}

\author{
Amalia Firdaus, Djoko Sulistiono, Ami Asparini, Moh. Singgih P. \\ Program Studi Diploma Teknik Sipil FTSP ITS, Surabaya \\ Email: amalia.wirawan@yahoo.com
}

\begin{abstract}
As one of the developing countries, Indonesia has more complex problems than the developed countries, ranging from the high population growth and social discrepancy to the lack of facilities and infrastructure that support the development, one of the problems related to the lack of facilities and infrastructure is the congestion occurring particularly at the intersection around Kuncir Bridge in Nganjuk Regency. Trips to Sedudo tourist site and other destinations will be highly disrupted if the access through the intersection is experiencing congestion. There are several things that should be known beforehand to overcome or at least to reduce traffic congestion, such as the causes of congestion, the negative effects arising and the efforts taken together to reduce the occurrence. Evaluation and control planning of the intersection refer to the Indonesian Highway Capacity Manual (MKJI - 1971). The evaluated variables of intersection performance are the capacity of intersection, the degree of saturated $(D S)$, the queue length $(Q L)$, the level of services (LOS), and the intersection delay. The scope and the results of the control planning activities of the roads around Kuncir Bridge in Nganjuk Regency include the evaluation of the existing condition of the roads around the intersection and the traffic engineering at the intersection around Kuncir Bridge when the evaluation is conducted (2015) and 5 years afterwards (2020).
\end{abstract}

Keywords: congestion, traffic engineering, roads, bridge, performance.

Abstrak

\begin{abstract}
Sebagai salah satu negara sedang berkembang, Indonesia mengalami permasalahanpermasalahan lebih kompleks dibandingkan dengan negara-negara maju, mulai dari pertumbuhan penduduk yang tinggi, kesenjangan sosial, hingga kurangnya sarana dan prasarana yang menunjang pembangunan itu sendiri. Kemacetan atau kongesti yang terjadi khususnya pada persimpangan jembatan Kuncir adalah salah satu diantaranya. Perjalanan ke tempat lokasi Wisata Sedudo maupun ketujuan perjalanan yang lain akan terganggu apabila akses melalui pertigaan tersebut mengalami kemacetan. Untuk mengatasi atau paling tidak mengurangi kemacetan lalu lintas perlu diketahui terlebih dahulu hal-hal yang menjadi penyebab timbulnya kemacetan lalu lintas, apa dampak negatif yang timbul akibatnya, dan bagaimana upaya yang dapat dilakukan bersama agar dapat mengurangi terjadinya kemacetan lalu lintas tersebut. Evaluasi dan perencanaan pengendalian simpang mengacu pada Manual Kapasitas Jalan Indonesia (MKJI - 1971). Variabel kinerja simpang yang akan dievaluasi adalah kapasitas simpang, derajat kejenuhan, panjang antrian tingkat pelayanan dan tundaan. Ruang lingkup dan hasil kegiatan perencanaan pengendalian jalan sekitar Jembatan Kuncir Nganjuk meliputi evaluasi kondisi jalan di sekitar persimpangan saat ini (eksisting) dan rekayasa lalu lintas pada pertigaan ruas jalan lokasi jembatan Kuncir pada kondisi eksisting (ketika evaluasi dilakukan tahun 2015) serta 5 tahun sesudahnya (2020).
\end{abstract}

Kata kunci: kemacetan, rekayasa lalu lintas, jalan, jembatan, kinerja.

1. Pendahuluan

Jalan sebagai prasarana transportasi merupakan prasarana yang amat penting bagi manusia. Lalu lintas kendaraan merupakan sarana untuk bergerak dari satu tempat ke tempat yang lain, oleh karena itu kemacetan lalu lintas merupakan salah satu masalah penting 
yang harus segera diatasi. Apabila arus lalu lintas terganggu atau terjadi kemacetan, maka mobilitas masyarakat juga akan mengalami gangguan. Masalah lalu lintas merupakan suatu masalah sulit yang harus dipecahkan bersama dan sangat penting untuk segera diselesaikan. Apabila masalah lalu lintas tidak terpecahkan, maka semua kerugian yang timbul akibat masalah ini akan ditanggung oleh masyarakat itu sendiri.

Berdasarkan hasil pengamatan lapangan, hal yang menimbulkan kemacetan disekitar Jembatan Kuncir salah satu diantaranya adalah pertemuan jalan dan jembatan pada Sungai Kuncir. Usaha mempermudah akses menuju tempat Wisata Sedudo telah dibangun Jembatan Kuncir. Akan tetapi karena lokasi jembatan terletak pada pertigaan jalan dan pertemuan sungai, maka akses ke lokasi wisata (Sedudo) atau tujuan perjalanan lain akan terganggu apabila akses melalui pertigaan tersebut mengalami kemacetan.

Maksud dan tujuan dari kegiatan perencanaan pengendalian lalu lintas jalan sekitar Jembatan Kuncir Nganjuk Jawa Timur adalah sebagai usulan dalam pengaturan lalu lintas pada lokasi tersebut, sehingga perjalanan orang/barang melalui pertigaan jalan tersebut dapat berjalan dengan aman dan lancar.

Variabel kinerja simpang (existing) yang akan dievaluasi adalah kapasitas simpang, derajat kejenuhan, panjang antrian, kendaraan terhenti, dan tundaan.
Perencanaan pengendalian lalu lintas jalan sekitar Jembatan Kuncir Nganjuk meliputi evaluasi kondisi jalan di sekitar pertigaan saat ini (eksisting) dan rekayasa lalu lintas pada pertigaan ruas jalan lokasi Jembatan Kuncir saat dilakukan evaluasi (2015) serta 5 tahun sesudahnya (2020).

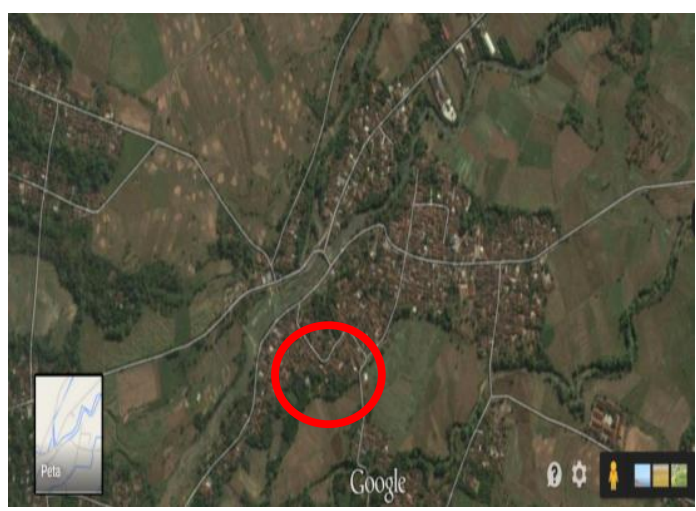

Gambar 1. Lokasi Jembatan Kuncir

\section{Metodologi}

Secara umum metodologi pelaksanaan kegiatan evaluasi dilaksanakan melalui tahapan sebagai berikut:

\section{Tahap persiapan}

Pada tahap persiapan ini merupakan tahap penyiapan ijin survei, pemahaman teori untuk pembahasan, surat - surat untuk memperoleh data sekunder, dan lain-lainya.

Pengumpulan Data Primer dan Sekunder

Pengumpulan data Sekunder meliputi:

- Pengumpulan data peraturan perundangan-undangan yang terkait dengan rekayasa lalu lintas.

- Data peraturan-peraturan dan studi terkait penataan kawasan setempat, misalnya RTRW Kabupaten, RDT- 
RK Kecamatan, Studi Jaringan Jalan, Master plan pengembangan jalan.

- Data karakteristik jalan setempat, jembatan yang baru dibuat, jumlah penduduk, karakteristik masyarakat dan ekonomi (PDRB) yang meliputi kondisi ekonomi kawasan.

Pengumpulan data Primer, data yang akan diambil secara langsung meliputi:

- Pengukuran panjang dan lebar jalan eksisting di sekitar Jembatan Kuncir.

- Pengukuran lebar dan panjang jembatan lama dan Jembatan Kuncir yang baru dibangun.

- Survey volume lalu lintas di sekitar Jembatan Kuncir.

- Survey kondisi tata guna lahan di sekitar Jembatan Kuncir.

\section{Pengolahan Data}

Pengolahan data dan analisa dilakukan berdasarkan data-data yang dibutuhkan, selanjutnya dikelompokkan sesuai identifikasi masalah, sehingga diperoleh pemecahan yang efektif dan terarah.

Pada Perancangan rekayasa lalu lintas sekitar Jembatan Kuncir menganalisis simpang tak bersinyal, simpang bersinyal dan bagian jalinan. Analisis ini memilih perancangan simpang yang paling efektif, aman, dan nyaman. Analisis tersebut mengacu pada MKJI 1997 dan beberapa literatur yang lainnya.

Evaluasi Kondisi Simpang tak Bersinyal

Berdasarkan kondisi geometrik jalan, jembatan eksisting, volume lalu lintas yang melewati jaringan jalan, kemudian dilakukan perhitungan dan simulasi simpang tanpa menggunakan sinyal (simpang tak bersinyal). Akan dianalisa dengan software kemungkinan persimpangan jalan dan Jembatan Kuncir tanpa menggunakan pengaturan lalulintas. Melalui analisa ini akan dapat di tentukan persimpangan di sekitar Jembatan Kuncir dapat menggunakan simpang tak bersimpang atau harus menggunakan simpang bersinyal.

\section{Analisa Simpang Bersinyal}

Tahapan berikutnya adalah analisa simpang di sekitar Jembatan Kuncir dengan menggunakan kondisi Simpang Bersinyal apabila hasil analisa sebelumnya dinyatakan tidak layak. Dengan menggunakan data-data yang ada yaitu data volume lalu lintas dalam bentuk asal dan tujuan perjalanan, panjang, dan lebar jalan (geometrik) akan dipakai untuk dianalisa dan disimulasikan simpang bersinyal pada jaringan jalan sekitar Jembatan Kuncir untuk tahun 2015 (eksisting) dan untuk kondisi tahun 2020. Manual Kapasitas Jalan Indonesia 1997 digunakan untuk menentukan Kinerja simpang. Apabila kinerja simpang tak bersinyal saat ini (2015) maupun 5 tahun kedepan (2020) sudah tidak memenuhi syarat maka perlu dilakukan evaluasi kinerja sebagai simpang bersinyal. Syarat kinerja simpang bersinyal meliputi Derajat Kejenuhan (DS) dan tundaan dan bila kriteria tersebut dipenuhi, maka selanjutnya dapat dilakukan desain simpang dan perbaikan geometri untuk kelancaran pergerakan kendaraan. Semua perhi- 
tungan dalam rangka evaluasi simpang tak bersinyal/bersinyal dilaksanakan dengan menggunakan program KAJI 1997. Hasil akhir dari evaluasi simpang bersinyal diperlihatkan dalam kesimpulan dan rekomendasi.

\section{Hasil dan Pembahasan}

Sesuai dengan tujuan yang hendak dicapai, maka pembahasan berikutnya adalah evaluasi simpang Jembatan Kuncir kondisi saat ini (eksisting), pemodelan simpang kondisi 2 fase, kondisi 3 fase, dan kondisi 4 fase.

Hasil pengukuran geometrik masingmasing ruas jalan sebagaimana terlihat pada Tabel 1.

Tabel 1. Kondisi Geometrik Simpang Jembatan Kuncir

\begin{tabular}{lccc}
\hline Nama Jalan & $\begin{array}{c}\text { Type } \\
\text { Lingkungan }\end{array}$ & $\begin{array}{c}\text { Hambatan } \\
\text { Samping }\end{array}$ & $\begin{array}{c}\text { Lebar } \\
(\mathrm{m})\end{array}$ \\
\hline J1. Sawahan & Residensial & Low & 5.5 \\
J1. Nganjuk & Residensial & Medium & 7.3 \\
J1. Ngetos & Residensial & Medium & 3.4 \\
J1. Brebek & Residensial & Medium & 4.3 \\
\hline
\end{tabular}

Sumber: Analisa hasil survey Januari 2015

Hasil perhitungan arus lalu lintas disajikan dalam bentuk tabel sebagaimana diperlihatkan dalam Tabel 2 dengan satuan kendaraan dan satuan mobil penumpang (smp) untuk tiap-tiap arahnya. Perhitungan arus lalu lintas yang dilakukan dari hasil survei merupakan Volume Puncak Pagi hasil perhitungan yang dilakukan tiap 15 menit.

Pertumbuhan lalu lintas di Kabupaten Nganjuk Diprediksi berdasarkan Data Penduduk, PDRB Kabupaten Nganjuk dalam angka tahun 2010 - 2012 kemu- dian dilakukan proses analisa regresi untuk mendapatkan angka pertumbuhannya, sehingga diperoleh pertumbuhan rata-rata sebesar $1.03 \%$ pertahun. Hasil prediksi volume untuk tahun 2020 sebagaimana terlihat pada Tabel 3.

Tabel 2. Volume lalu lintas (kendaraan/jam)

\begin{tabular}{lcccc}
\hline Jenis Kendaran/ & LV & HV & MC & UM \\
Arah Pergerakan & & & & \\
\hline SWH-NGK & 80 & 14 & 891 & 7 \\
SWH - BBK & 1 & 1 & 67 & 1 \\
SWH - NGT & 2 & 2 & 70 & 2 \\
BBK - NGT & 3 & 1 & 75 & 1 \\
BBK - SWH & 9 & 2 & 300 & 3 \\
BBK - NGK & 3 & 2 & 128 & 2 \\
NGK - BBK & 7 & 5 & 134 & 2 \\
NGK - NGT & 6 & 4 & 129 & 1 \\
NGK - SWH & 44 & 9 & 353 & 2 \\
NGT - SWH & 2 & 1 & 59 & 1 \\
NGT - NGK & 8 & 2 & 225 & 2 \\
NGT - BBK & 2 & 2 & 201 & 2 \\
\hline Sumber: Analisa hasil survey Januari 2015 \\
Keterangan: \\
SWH : Sawahan \\
NGK : Nganjuk \\
BBK : Berbek \\
NGT :
\end{tabular}

Evaluasi kinerja simpang lokasi Jembatan Kuncir sebagai simpang tak bersinyal tidak dapat dilakukan, sehubungan adanya jembatan yang sempit dengan lebar $4 \mathrm{~m}$ serta ruas jalan yang cukup sempit yaitu $3,5 \mathrm{~m}$. 
Tabel 3. Volume lalu lintas (kendaraan/jam) Hasil analisa regresi tahun 2015

\begin{tabular}{ccccc}
\hline $\begin{array}{c}\text { Jenis Kendaraan/ Arah } \\
\text { Pergerakan }\end{array}$ & LV & HV & MC & UM \\
\hline SWH-NGK & 81 & 15 & 893 & 9 \\
\hline SWH - BBK & 3 & 3 & 69 & 3 \\
\hline SWH - NGT & 4 & 4 & 72 & 4 \\
\hline BBK - NGT & 5 & 3 & 77 & 3 \\
\hline BBK - SWH & 11 & 4 & 302 & 5 \\
\hline BBK - NGK & 5 & 4 & 129 & 4 \\
\hline NGK - BBK & 9 & 7 & 136 & 4 \\
\hline NGK - NGT & 8 & 6 & 131 & 3 \\
\hline NGK - SWH & 45 & 11 & 354 & 4 \\
\hline NGT - SWH & 4 & 3 & 61 & 3 \\
\hline NGT - NGK & 10 & 4 & 227 & 4 \\
\hline NGT - BBK & 4 & 4 & 203 & 4 \\
\hline Sur Hasil prediks & & & &
\end{tabular}

Sumber: Hasil prediksi

Tanpa adanya APILL (Alat Pemberi Isyarat Lalu Lintas), pergerakan kendaraan dari arah Sawahan ke arah Nganjuk atau ke arah Berbek dan Ngetos melalui jembatan dan ruas jalan yang sempit, tidak dapat dilakukan. Penanganan belok kanan dari arah Sawahan dengan putaran $U$ ( $U$-Turn) juga tidak memungkinkan karena faktor lebar jalan dari arah Nganjuk, Terutama untuk kendaraan Berat (Heavy Vehicle) seperti Bus dan Truk, sehingga Pengaturan simpang bersinyal dengan APILL perlu dilakukan.

Analisis data yang akan dilakukan adalah dengan menganalisis data hasil survei dengan pendekatan MKJI 1997 dengan langkah-langkah analisis sesuai dengan diagram alir seperti terlihat pada Gambar 2.

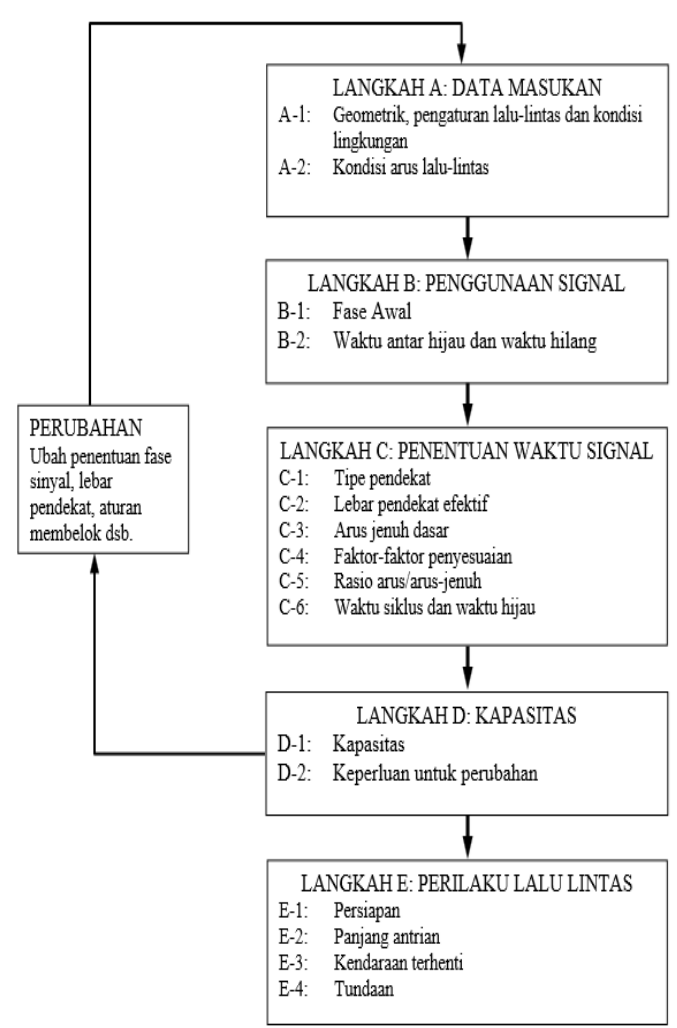

Gambar 2. Langkah - Langkah Penyelesaian Simpang Bersinyal

Evaluasi kinerja simpang bersinyal eksisting dilakukan dengan memanfaatkan kondisi geometrik pendekat atau lengan simpang eksisting atau yang ada saat ini. Kondisi Geometrik dan Lingkungan disesuaikan untuk kebutuhan simpang bersinyal, lihat Tabel 4. Dari data pada Tabel 4, beberapa lebar pendekat tidak memenuhi syarat minimal lebar jalan perkotaan menurut RSNI T-14 2004 yaitu 5,5 m. Demikian juga default minimal input data dalam software KAJI 1997, sehingga data masukan tidak dapat sesuai data lapangan melainkan mengikuti default minimal software. 
Evaluasi kinerja Lalu lintas dilakukan dengan pengaturan 3 fase dan 4 fase, dengan hasil sebagaimana Tabel 5.
Kemudian evaluasi kinerja simpang bersinyal kondisi existing untuk 5 tahun mendatang yaitu tahun 2020, Hasil evaluasi dapat dilihat pada Tabel 6.

Tabel 4. Geometrik dan simpang bersinyal kondisi eksisting (2015)

\begin{tabular}{lccccccc}
\hline Kode Pendekat & Type Pendekat & Median & LTOR & $\begin{array}{c}\text { Lebar } \\
(\mathrm{m})\end{array}$ & $\begin{array}{c}\text { Lebar } \\
\text { Masuk } \\
(\mathrm{m})\end{array}$ & $\begin{array}{c}\text { Lebar } \\
\text { LTOR } \\
(\mathrm{m})\end{array}$ & $\begin{array}{c}\text { Lebar } \\
\text { Keluar } \\
(\mathrm{m})\end{array}$ \\
\hline Jl. Sawahan & Residensial & Tidak & Ya & 5.5 & 2.75 & 2.75 & 2.75 \\
Jl. Berbek & Residensial & Tidak & Tidak & 2.15 & 2.15 & 1.7 \\
Jl. Nganjuk & Residensial & Tidak & Tidak & 4.55 & 4.55 & 5 \\
Jl. Ngetos & Residensial & Tidak & Tidak & 1.7 & 1.7 & 2.15 \\
\hline
\end{tabular}

Tabel 5. Hasil evaluasi kinerja simpang bersinyal kondisi eksisting tahun 2015

\begin{tabular}{|c|c|c|c|c|c|c|c|}
\hline Fase & Pendekat & $\begin{array}{l}\text { CT } \\
\text { (dt) }\end{array}$ & DS & $\mathrm{NQ}_{\max }(\mathrm{smp})$ & $\begin{array}{l}\text { QL } \\
\text { (m) }\end{array}$ & $\begin{array}{l}\text { Mean DI } \\
\text { (smp/dt) }\end{array}$ & LOS \\
\hline \multirow{4}{*}{3} & Sawahan & \multirow{4}{*}{70} & 0.15 & 1 & 7 & \multirow{4}{*}{23.37} & \multirow{4}{*}{$\mathrm{C}$} \\
\hline & Berbek & & 0.656 & 6 & 48 & & \\
\hline & Nganjuk & & 0.479 & 5 & 22 & & \\
\hline & Ngetos & & 0.598 & 5 & 40 & & \\
\hline \multirow{4}{*}{4} & Sawahan & \multirow{4}{*}{80} & 0.172 & 1 & 7 & \multirow{4}{*}{25.7} & \multirow{4}{*}{ D } \\
\hline & Berbek & & 0.561 & 4 & 32 & & \\
\hline & Nganjuk & & 0.435 & 6 & 26 & & \\
\hline & Ngetos & & 0.595 & 4 & 32 & & \\
\hline
\end{tabular}

Tabel 6. Hasil evaluasi kinerja simpang bersinyal kondisi Tahun 2020

\begin{tabular}{|c|c|c|c|c|c|c|c|}
\hline Fase & Pendekat & $\begin{array}{l}\text { CT } \\
(\mathrm{dt})\end{array}$ & DS & $\begin{array}{l}\mathrm{NQ}_{\max } \\
\text { (smp) }\end{array}$ & $\begin{array}{l}\text { QL } \\
\text { (m) }\end{array}$ & $\begin{array}{l}\text { Mean DI } \\
(\mathrm{smp} / \mathrm{dt})\end{array}$ & LOS \\
\hline \multirow{4}{*}{3} & Sawahan & \multirow{4}{*}{71} & 0.195 & 1 & 7 & \multirow{4}{*}{24.63} & \multirow{4}{*}{$\mathrm{C}$} \\
\hline & Berbek & & 0.691 & 7 & 56 & & \\
\hline & Nganjuk & & 0.524 & 6 & 26 & & \\
\hline & Ngetos & & 0.628 & 6 & 48 & & \\
\hline \multirow{4}{*}{4} & Sawahan & \multirow{4}{*}{80} & 0.22 & 1 & 7 & \multirow{4}{*}{28.06} & \multirow{4}{*}{$\mathrm{D}$} \\
\hline & Berbek & & 0.627 & 5 & 40 & & \\
\hline & Nganjuk & & 0.455 & 6 & 26 & & \\
\hline & Ngetos & & 0.679 & 5 & 40 & & \\
\hline
\end{tabular}


Tabel 7. Hasil evaluasi kinerja simpang bersinyal Dengan perbaikan geometrik tahun 2015

\begin{tabular}{|c|c|c|c|c|c|c|c|}
\hline Fase & Pendekat & $\begin{array}{l}\text { CT } \\
\text { (dt) }\end{array}$ & DS & $\begin{array}{l}\mathrm{NQ}_{\max } \\
\text { (smp) }\end{array}$ & $\begin{array}{l}\text { QL } \\
\text { (m) }\end{array}$ & $\begin{array}{c}\text { DI } \\
(\mathrm{smp} / \mathrm{dt})\end{array}$ & LOS \\
\hline \multirow{4}{*}{2} & Sawahan & \multirow{4}{*}{55} & 0.283 & 1 & 7 & \multirow{4}{*}{19.17} & \multirow{4}{*}{ C } \\
\hline & Berbek & & 0.596 & 4 & 29 & & \\
\hline & Nganjuk & & 0.598 & 7 & 25 & & \\
\hline & Ngetos & & 0.546 & 4 & 29 & & \\
\hline \multirow{4}{*}{3} & Sawahan & \multirow{4}{*}{77} & 0.165 & 1 & 7 & \multirow{4}{*}{21.35} & \multirow{4}{*}{ C } \\
\hline & Berbek & & 0.482 & 5 & 36 & & \\
\hline & Nganjuk & & 0.436 & 6 & 22 & & \\
\hline & Ngetos & & 0.441 & 5 & 36 & & \\
\hline \multirow{4}{*}{4} & Sawahan & \multirow{4}{*}{80} & 0.143 & 1 & 7 & \multirow{4}{*}{25.7} & \multirow{4}{*}{ D } \\
\hline & Berbek & & 0.612 & 4 & 32 & & \\
\hline & Nganjuk & & 0.351 & 6 & 26 & & \\
\hline & Ngetos & & 0.54 & 4 & 32 & & \\
\hline
\end{tabular}

Sumber: Hasil Perhitungan

Pengaturan simpang dengan memberikan APILL atau menjadi simpang bersinyal disertai perbaikan geometrik simpang, dengan pengaturan 2 fase, 3 fase, dan 4 fase. Sesuai Tabel 7, pada penyelesaian dengan 2 fase, 3 fase, atau 4 fase, perbaikan yang dilakukan adalah dengan penyesuaian standar lebar jalan setiap pendekat. Pada Pendekat Jl. Sawahan dan Jl. Nganjuk menjadi total $8,25 \mathrm{~m}$ (W masuk 5,5 m sisanya untuk W keluar dari Volume pendekat lain tanpa median) dan pada pendekat Jl. Berbek dan Jl. Ngetos diperlebar menjadi 5,5 m (untuk 2 jalur tanpa median) sesuai standar yang berlaku untuk Jalan Perkotaan.

Pada pendekat Jl. Sawahan diberlakukan LTOR (Left Turn On Red) atau lurus ke arah Nganjuk boleh berjalan terus.

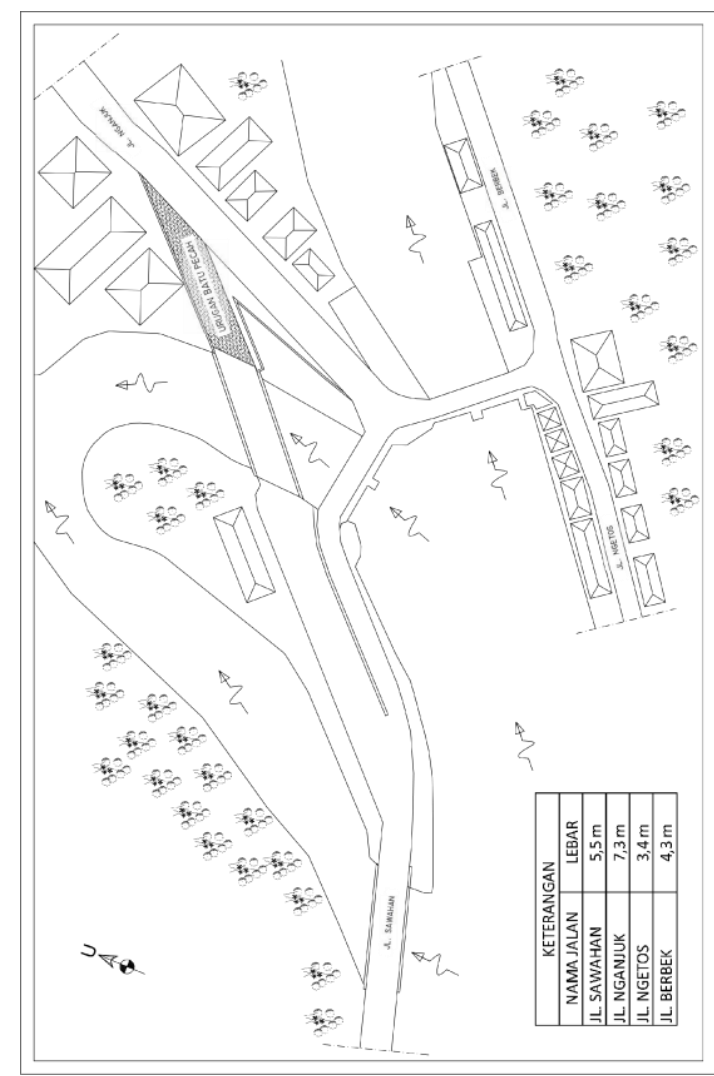

Gambar 3. Geometrik Eksisting Simpang Jembatan kuncir

1

Jurnal APLIKASI: Media Informasi \& Komunikasi Aplikasi Teknik Sipil Terkini 
2

Sedangkan pada pendekat lain, karena keterbatasan lebar geometrik dan pembatasan gerakan belok pada setiap fase terutama fase 2 dan 3 , diberlakukan belok kiri mengikuti lampu. Analisa kinerja lalu lintas untuk 5 tahun kedepan (2015) yaitu pada tahun 2020 dengan hasil sebagaimana Tabel 8 .

Tabel 8. Hasil evaluasi kinerja simpang bersinyal Dengan perbaikan geometrik tahun 2020

\begin{tabular}{|c|c|c|c|c|c|c|c|}
\hline Fase & Pendekat & $\begin{array}{l}\text { CT } \\
(\mathrm{dt})\end{array}$ & DS & $\begin{array}{c}\text { NQ max } \\
\text { (smp) }\end{array}$ & $\begin{array}{l}\text { QL } \\
\text { (m) }\end{array}$ & $\begin{array}{c}\text { DI } \\
(\mathrm{smp} / \mathrm{dt})\end{array}$ & LOS \\
\hline \multirow{4}{*}{2} & Sawahan & \multirow{4}{*}{55} & 0.336 & 1 & 7 & \multirow{4}{*}{20.07} & \multirow{4}{*}{$\mathrm{C}$} \\
\hline & Berbek & & 0.666 & 5 & 36 & & \\
\hline & Nganjuk & & 0.615 & 7 & 25 & & \\
\hline & Ngetos & & 0.532 & 4 & 29 & & \\
\hline \multirow{4}{*}{3} & Sawahan & \multirow{4}{*}{77} & 0.211 & 1 & 7 & \multirow{4}{*}{22.03} & \multirow{4}{*}{$\mathrm{C}$} \\
\hline & Berbek & & 0.526 & 6 & 44 & & \\
\hline & Nganjuk & & 0.485 & 6 & 22 & & \\
\hline & Ngetos & & 0.481 & 5 & 36 & & \\
\hline \multirow{4}{*}{4} & Sawahan & \multirow{4}{*}{80} & 0.22 & 1 & 7 & \multirow{4}{*}{28.06} & \multirow{4}{*}{ D } \\
\hline & Berbek & & 0.627 & 5 & 40 & & \\
\hline & Nganjuk & & 0.455 & 6 & 26 & & \\
\hline & Ngetos & & 0.679 & 5 & 40 & & \\
\hline
\end{tabular}

Sumber: Hasil Perhitungan

Dari Tabel 8 terlihat bahwa perubahan kinerja lalu lintas dalam 5 tahun. Terdapat sedikit perubahan pada Mean Intersection Delay tetapi Tingkat Pelayanan/LOS (Level of Services) tetap pada semua fase dan semua DS masih < 0,75 masih standar yang ada.

\section{Simpulan}

Dari hasil analisis dan evaluasi kinerja simpang pada kondisi eksisting (2015) di sekitar Jembatan Kuncir Kabupaten Nganjuk, maka dapat disimpulkan sebagai berikut:

1. Pengaturan simpang tak bersinyal pada kondisi existing (2015) tidak dapat dilakukan sehubungan adanya jembatan yang sempit dengan lebar
$4 \mathrm{~m}$ serta ruas jalan yang cukup sempit dengan lebar 3,5 m. Tanpa adanya APILL (Alat Pemberi Isyarat Lalu Lintas) pergerakan dari arah Sawahan ke Nganjuk, Berbek dan Ngetos tidak dapat dilakukan. Penanganan belok kanan dari arah Sawahan dengan putaran U juga tidak memungkinkan karena lebar jalan ke arah Nganjuk yang sempit.

2. Pengaturan simpang bersinyal pada kondisi eksisting tanpa perbaikan geometrik lebih memungkinkan, karena pengaturan dengan 3 fase pada saat ini (th. 2015) dan 5 tahun mendatang (th. 2020) memberi Tingkat Pelayanan/LOS C dengan cycle time 70 detik (masuk dalam 
syarat 3 fase sebesar $50-100 \mathrm{dt}$ ). DS pada semua pendekat $<0,75$ dan Mean Intersection Delay $=23,37$ smp/detik. Pengaturan dengan 4 fase pada saat ini (2015), dan 5 tahun mendatang (2020) memberikan Tingkat Pelayanan LOS D.

3. Pengaturan simpang bersinyal pada kondisi eksisting (2015) dan dengan perbaikan geometrik dengan pengaturan 2 dan 3 fase saat ini (2015) sampai dengan 5 tahun mendatang (2020) didapatkan LOS C, sedangkan untuk pengaturan 4 fase memberikan tingkat pelayanan $\mathrm{D}$ baik tahun eksisiting (2015) maupun 5 tahun mendatang (2020).

Sesuai hasil perhitungan maka rekomendasi yang bisa diberikan adalah:

1. Pengaturan jika tetap dengan lebar eksisting, maka kondisi pergerakan lalu lintas yang disarankan adalah dengan pengaturan 3 fase dengan LOS (Level of Services) C Mean Intersection Delay estimasi nya setiap kendaraan mencapai 23,37 smp/dt dan panjang antrian (QL, Queue Length) mencapai $48 \mathrm{~m}$ dan DS (Degree of Saturated) terbesar mencapai 0,656 pada pendekat Jalan Berbek.

2. Pengaturan lalu lintas jika melakukan perbaikan dengan pelebaran minimal sesuai standar yang berla$\mathrm{ku}$, maka dipilh 3 fase dengan LOS (Level of Services) C pada tahun 2015, dengan Mean Intersection Delay setiap kendaraan mencapai 21,35 smp/dt dan panjang antrian
(QL, Queue Length) mencapai $36 \mathrm{~m}$ dan DS (Degree of Saturated) terbesar mencapai 0,482 pada pendekat Jalan Berbek. Pelayanan pada th 2020 masih LOS C, dan masih memenuhi standar jalan perkotaan DS $<0.75$. Pemilihan 3 fase, dengan Mean Intersection Delay lebih besar dari pengaturan 2 fase, didasarkan pada pertimbangan dapat meminimalisir terjadinya Titik konflik antar pendekat.

\section{Daftar Pustaka}

Direktorat Jenderal Bina Marga dan Direktorat Bina Jalan Kota. (1997). Manual Kapasitas Jalan Indonesia (MKJI). Jakarta.

RSNI - T14 - 2004. Geometri Jalan Perkotaan. Jakarta. 
